\title{
Electrospark Coatings Based on WC-Co Alloys with Aluminium Oxide and Carbon Additives
}

\author{
Sergey A. Pyachin, Sergey V. Nikolenko, Alexander A. Burkov ${ }^{*}$, Nikolay A. Suy \\ Institute of Materials, Khabarovsk Scientific Centre, Far East Branch, Russian Academy of Sciences, Khabarovsk, Russia. \\ Email: "burkovalex@mail.ru
}

Received December $12^{\text {th }}, 2012$; revised January $14^{\text {th }}, 2013$; accepted February $18^{\text {th }}, 2013$

\begin{abstract}
The structure and properties of coatings based on WC-Co alloys containing additives of $1 \%-5 \%$ aluminium oxide and $2.5 \%-4.5 \%$ carbon were investigated. The coatings had a nanocrystalline structure. Depending on the duration and frequency of the discharge pulses, the ratio between $\mathrm{WC}$ and $\mathrm{W}_{2} \mathrm{C}$ in the coatings was different. The additives in the hard alloy allowed us increase the microhardness and wear resistance of the coatings by a factor of $2-3$ in comparison to coatings created using a conventional WC- $10 \%$ Co alloy.
\end{abstract}

Keywords: Electrospark Deposition; Coatings; Tungsten Carbide; Carbon; Aluminium Oxide; Wear; Microhardness

\section{Introduction}

The deposition of wear-resistant electrospark coatings, including nanostructured ones, on the surfaces of machine parts and tools makes it possible to increase their operating lifespan considerably [1-3]. Tungsten carbidebased hard alloys with cobalt binders have become widespread as electrode materials for the fabrication of coatings [4-8]. However, these electrode materials have a high erosion resistance and transfer poorly to the cathode. In addition, cracks often form in the hardened deposited layers under thermal stress when the discharges bombard the cathode. Nanopowder additives of refractory compounds in hard alloys positively affects their microstructure and the tribological characteristics of electrospark coatings [6]. Aluminium oxide, as a simple chemical compound with a high chemical inertness and temperature stability, is an ideal coating component for protection of a hard alloy from the impact of high temperature and chemical wear. An additive of aluminium oxide can also be used as an inhibitor of grain growth [9]. Increasing the $\mathrm{Al}_{2} \mathrm{O}_{3}$ content in the electrode material from $1 \%$ to $5 \%$ leads to a decrease in the average grain size from 2.4 to $0.8 \mu \mathrm{m}$. Decreasing the grain size of tungsten carbide should lead to an increase in the strength of the hard alloy and also of coatings created on this basis. For example, electrospark coatings created with a nanostructured WC-Co electrode onto an Armco iron were found to exhibit a uniform amorphous structure, higher wear resistance, and reduced friction coefficient as compared to those deposited with conventional microstructured WC-Co

${ }^{*}$ Corresponding author. electrodes [7].

On the other hand, it is known that tungsten carbide (WC) decomposes to $\mathrm{W}_{2} \mathrm{C}$ and tungsten under the discharge action, and therefore the composition of the coating is different from the initial composition of the treating electrode, that is, the anode $[7,8,10]$. The decarburization of tungsten carbide reduces the wear resistance of coatings. With increasing power evolving at discharge, the $\mathrm{W}_{2} \mathrm{C}$ carbide content of the deposited coating increases. If argon is applied as a protective environment for electrospark processing, the degradation of the tungsten carbide WC decreases but negligibly. Therefore it is necessary to find new ways to diminish the influence of this negative phenomenon.

The major aim of these examinations was to determine the effects of aluminium oxide and carbon additives in the electrode material on the properties of the resulting electrospark coatings.

\section{Material and Methods}

\subsection{Electrode Materials}

In our work, electrode materials based on tungsten carbide and cobalt were sintered by the conventional technology of powder metallurgy. Three sets of samples were prepared. The first series of electrodes were of the standard WC- $10 \%$ Co hard alloy. The second series consisted of the WC- $10 \%$ Co hard alloy with $1 \%, 3 \%$, and $5 \%$ $\mathrm{Al}_{2} \mathrm{O}_{3}$ additives. In the third series, all powder mixtures of $\mathrm{W}, \mathrm{Co}$, and $\mathrm{C}$ were prepared so that the cobalt content was constant $(10 \mathrm{wt} \%)$ and the carbon concentration was 
varied (2.5 and $4.5 \mathrm{wt} \%)$. The powder mixtures were mixed by a PM400 planetary ball mill (Germany) at a rotational velocity of $250 \mathrm{rpm}$ during $30 \mathrm{~min}$ with the addition of $5 \mathrm{ml}$ of isopropyl alcohol. The obtained powders were mixed with a solution of rubber in gasoline and then pressed using a Test Press-250M (Russia) with a load of $30 \mathrm{kN}$. The masses of the samples made for sintering were identical and equalled $13 \mathrm{~g}$. The pressed mixtures were sintered in a Carbolite STF vacuum tube oven (England) at $1400^{\circ} \mathrm{C}$ during $8 \mathrm{~h}$. The hard alloy sticks used as electrodes had sizes of $40 \times 5 \times 5 \mathrm{~mm}^{3}$. The mass losses from the sintered samples (induced by plasticizer evaporation and the burning of carbon, tungsten, and cobalt due to the presence of residual oxygen and crystallization water in the initial powders) were $4 \%$ on average.

\subsection{Coating Deposition and Characterization}

The substrates employed were $10 \times 10 \times 5 \mathrm{~mm}^{3}$ plates of medium-carbon steel 35 . The coatings were deposited manually in air by an EMIS (Russia) setup. The interelectrode voltage during the pulses was maintained at 40 $\mathrm{V}$. The discharge current amplitude was $100 \mathrm{~A}$, while the repetition frequencies of the pulses $(f)$ were 100 or 1000 $\mathrm{Hz}$. The pulse-on length $(\tau)$ ranged from 10 to $100 \mu \mathrm{s}$, the frequency of the anode vibrator was $100 \mathrm{~Hz}$, and the total processing time was 2 - $20 \mathrm{~min}$. To control the mass transfer from the anode to the cathode, after every $60 \mathrm{~s}$ the deposition process was interrupted and the electrodes were weighed separately by an electronic balance (Vibra HTR-220CE) with accuracy up to $10^{-4} \mathrm{~g}$.

The microstructure and chemical composition of the coatings were analysed using an optical microscope and an EVO $40 \mathrm{HV}$ scanning electron microscope (SEM) (Carl Zeiss, Germany) with an INCA Energy 350 energydispersion spectrometer (Oxford Instruments, UK). The phase composition of the produced coatings was examined by a DRON-7 X-ray diffractometer (Burevestnik, Russia) equipped with a $\mathrm{Cu}-\mathrm{K} \alpha$ radiation source in Bragg-Brentano geometry. The coating surfaces were also investigated by AFM microscopy (NT-MTD Company). Microhardness was measured by the Vickers method with a PMT-3M tester (Russia) under a load of $50 \mathrm{~N}$. The abrasive wear resistance of the electrospark coatings was measured by a Calotest friction machine (CSM Instruments, Switzerland) using the "ball-plate" scheme [11]. A ball with a diameter of $30 \mathrm{~mm}$ was rotated at a linear velocity of $0.27 \mathrm{~m} / \mathrm{s}$. Aluminium oxide powder in solar oil was employed as an abrasive material.

\section{Results and Discussion}

\subsection{Microstructure of Coatings}

The microstructures of the created coatings are presented in Figure 1. After etching by $4 \%$ nitric acid in ethanol, we observed the ferrite-pearlite structure of the steel substrate; after etching with a mixture of sodium hydroxide and potassium ferricyanide (III), the microstructure is seen in the deposited layer. The white layer contains sections with dispersed iron carbides and aggregations of anode decomposition products. The main part of the surface layer consists of carbide $\mathrm{W}_{2} \mathrm{C}$ (the gray area in the upper part of the coating) with small inclusions of carbide WC. Figure 2 SEM images of the surface and crosssections of the obtained coatings show the presence of white grains whose elemental composition corresponds to tungsten carbide (WC). Moreover, the quantity of these grains is much larger in the $\mathrm{WC}-10 \% \mathrm{Co}-4.5 \% \mathrm{C}$ coating than in the $\mathrm{WC}-10 \%$ Co coating. With increasing carbon content in the electrode, its concentration in the congruous coating increased, since the carbon concentration in the coating on the WC- $10 \% \mathrm{Co}-4.5 \% \mathrm{C}$ sample ranged from 30 to 40 at.\%, while that obtained using the standard WC-10\%Co electrode was $26-31$ at $\%$. The structure of the surface layers deposited by the application of anodes with higher carbon contents was more uniform, although there were some micropores. Thus, the addition of carbon into the electrode materials can increase its content in the coating and prevent decarburization of tungsten carbide due to saturation of the iron present in the coating by additional carbon.

The average thickness of the obtained coatings was 7 $80 \mu \mathrm{m}$ (Table 1). The thickness of the coating increased with increasing impulse duration.

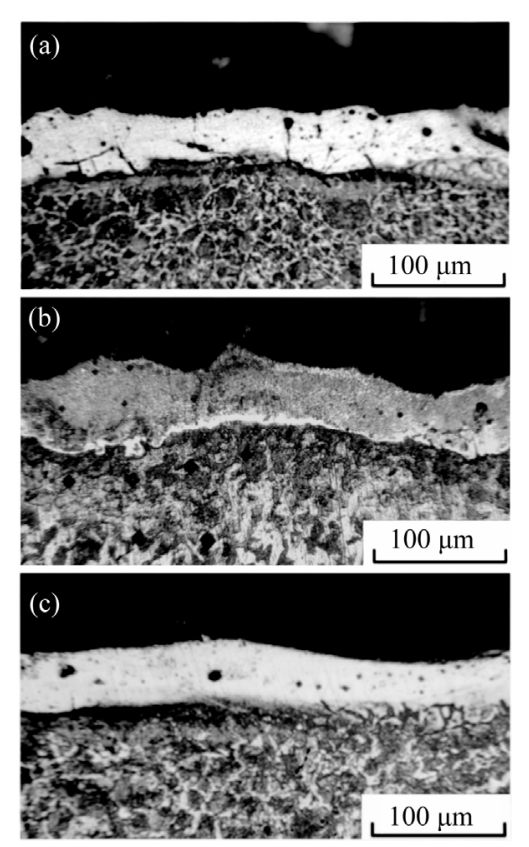

Figure 1. Cross-sectional views of electrospark coatings: (a) WC-10\%Co; (b) WC-10\%Co-3\% $\mathrm{Al}_{2} \mathrm{O}_{3}$; (c) WC-10\%Co4.5\% $\mathrm{C}$. 


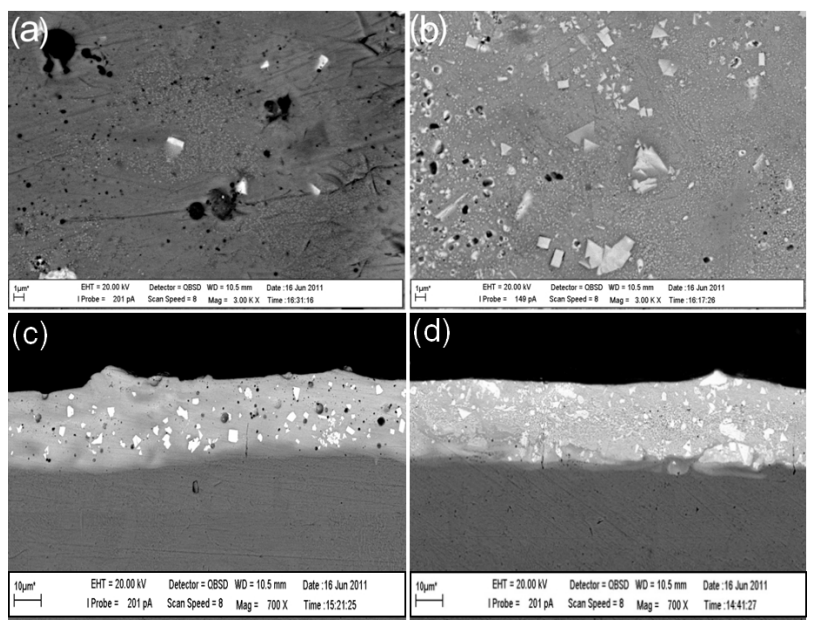

Figure 2. SEM images of the surface ((a) and (b)) and crosssection ((c) and (d)) of coatings deposited with electrodes WC$10 \% \mathrm{Co}((\mathrm{a})$ and (c)) and WC-10\%Co-4.5\%C ((b) and (d)).

Table 1. Characteristics of coatings created by electrospark deposition onto steel 35.

\begin{tabular}{ccccc}
\hline Anode & $\begin{array}{c}\text { Impulse } \\
\text { Length }(\mu \mathrm{s})\end{array}$ & $\begin{array}{c}\text { Average } \\
\text { Thickness } \\
(\mu \mathrm{m})\end{array}$ & $\begin{array}{c}\text { Average } \\
\text { Microhardness } \\
(\mathrm{GPa})\end{array}$ & $\begin{array}{c}\text { Wear } \\
\text { Resistance } \\
\left(\mathrm{N} \cdot \mathrm{m} / \mathrm{cm}^{3}\right)\end{array}$ \\
\hline $\mathrm{WC}-10 \% \mathrm{Co}$ & 20 & 7 & 7 & 2 \\
& 80 & 20 & 12 & 5 \\
$\mathrm{WC}-10 \% \mathrm{Co}-$ & 40 & 18 & 13 & 15 \\
$1 \% \mathrm{Al}_{2} \mathrm{O}_{3}$ & 80 & 18 & 11 & 40 \\
$\mathrm{WC}-10 \% \mathrm{Co}-$ & 40 & 21 & 11 & 9 \\
$3 \% \mathrm{Al}_{2} \mathrm{O}_{3}$ & 80 & 38 & 13 & 35 \\
$\mathrm{WC}-10 \% \mathrm{Co}-$ & 40 & 25 & 11 & 14 \\
$5 \% \mathrm{Al}_{2} \mathrm{O}_{3}$ & 80 & 37 & 12 & 28 \\
$\mathrm{WC}-10 \% \mathrm{Co}$ & 100 & 35 & 16 & 60 \\
$\mathrm{WC}-10 \% \mathrm{Co}-$ & 100 & 40 & 14 & 73 \\
$2.5 \% \mathrm{C}$ & & & 14 & 77 \\
$\mathrm{WC}-10 \% \mathrm{Co}-$ & 100 & 37 & & \\
$4.5 \% \mathrm{C}$ & & & & \\
\hline
\end{tabular}

Upon metallographic analysis of a transverse section of a cathode with an alloyed surface layer, we found pores and microcracks in the surface layer; the structure was nonuniform over the thickness. The damage to the surface layers increased as the discharge energy evolved. The microcracks were formed due to the difference between the coefficients of thermal expansion for the coating and the steel substrate.

A ferrite-perlite structure was observed on the fragments of steel adjoining the deposited layer. The perlite component is subjected to quenching as a result of the thermal effect and rapid cooling. The section adjacent to the white layer is subject to the thermal action of the discharge and plasma, followed by rapid cooling. As a result, we observed thin layers in which the pearlite component was quenched. The microhardness was increased in that region (Figure 1).

\subsection{AFM Investigations}

Because the deposited surface layer is relatively rough and scanning probe microscopes cannot be used to study such surfaces, all the samples were given a preliminary assessment on a confocal microscope attached to the SPM. As a result, samples suitable for study using an SPM were selected, and regions on the surface of the alloyed layer where nanostructuring preferentially occurs during electrospark alloying could be identified; they are distinguished by their color (ranging up to blue; Figure 3(a)). On the scan obtained by the scanning probe microscope (Figure 3(b)), we observed that the nanoparticles were smallest when the electrode consisted of the WC$10 \%$ Co- $3 \% \mathrm{Al}_{2} \mathrm{O}_{3}$ alloy. The minimum particle size was $30 \mathrm{~nm}$. The figures given in Figure 3(c) characterize the adhesion of individual particles. With constant phase composition, increases in this parameter confirm decreases in the size of the nanoparticles.

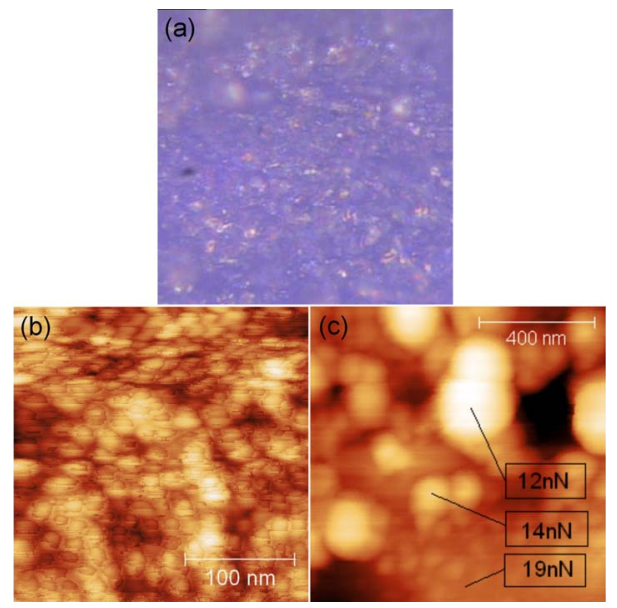

Figure 3. Image of the nanostructured surface of the WCCo-3\% $\mathrm{Al}_{2} \mathrm{O}_{3}$ coating: (a) View by confocal microscopy; (b) AFM scan; (c) AFM scan with representation of the adhesion of individual particles.
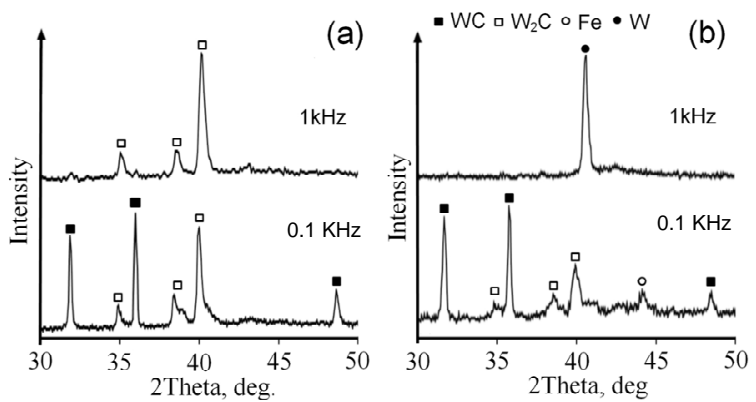

Figure 4. XRD patterns of the coatings obtained by electrospark deposition with (a) WC-10\%Co and (b) WC-10\%Co$3 \mathrm{Al}_{2} \mathrm{O}_{3}$ at different frequencies. 


\subsection{RFA Analysis}

Investigation of the phase composition of the coatings (Figure 4) showed that the coatings are based on the carbides $\mathrm{W}_{2} \mathrm{C}$ with small $\mathrm{WC}$ inclusions. The decomposition of tungsten carbide WC to carbide $\mathrm{W}_{2} \mathrm{C}$ is observed in local sites as an effect of the electric discharges due to heat liberation and the intensification of the interaction between the electrode material and oxygen in the air. Also, decarburization can occur upon the interaction of WC with the iron substrate, which has been observed for electrospark deposition [7] and HVOF spraying [11]. The compositions of the obtained coatings were different. Such variations started to manifest themselves in an especially pronounced manner as the duration and frequency of the discharge pulses increases. The decarburization of the hard alloy was intense at a higher discharge frequency of $1 \mathrm{kHz}$. The WC- $10 \%$ Co coating created at this frequency consisted almost completely of $\mathrm{W}_{2} \mathrm{C}$ together with small amounts of WC, in contrast to the same coating deposited at $0.1 \mathrm{kHz}$. WC carbide dominated over semicarbide $\mathrm{W}_{2} \mathrm{C}$ in the coating composition at a frequency of $0.1 \mathrm{kHz}$. At high frequencies $(1 \mathrm{kHz})$ and short lengths $(<20 \mu \mathrm{s})$, the surrounding gas medium exerts no substantial effect.

When electrodes with excess carbon (WC- $10 \% \mathrm{Co}-$ $2.5 \% \mathrm{C}$ or $\mathrm{WC}-10 \% \mathrm{Co}-4.5 \% \mathrm{C}$ ) were used, tungsten carbide $\mathrm{WC}$ dominated in the electrospark coatings. Thus, the addition of carbon into the electrode $\mathrm{WC}-10 \% \mathrm{Co}$ material allowed the amount of the WC phase in the deposited layers to increase (Figure 5).

\subsection{Properties of Electrospark Coatings}

Microhardness was measured in a skewed section of samples with coatings. It was established that the microhardness of the $\mathrm{WC}-10 \% \mathrm{Co}-\mathrm{Al}_{2} \mathrm{O}_{3}$ coatings is approximately equal, and greater than that of the steel matrix (2.2 GPa) by a factor of 5 - 6 (Table 1). It can be seen that the microhardness of the electrospark coatings deposited decreased with increasing carbon content in the anode materials. This is explained by the fact that there is more $\mathrm{WC}$ in these coatings and $\mathrm{W}_{2} \mathrm{C}$ is a harder phase as compared to WC but is also brittle. An analysis of the experimental results of wear tests (Table 1) shows that the use of the WC- $8 \%$ Co hard alloy with the aluminium oxide additive as the electrode material allowed us to increase the wear resistance by a factor of four or more in comparison with the steel substrate. Increasing the discharge duration increased the thickness of the coating and its wear resistance.

The excess carbon in the hard alloys increased the wear resistance of the coatings 1.5 fold. The WC$10 \% \mathrm{Co}-2.5 \% \mathrm{C}$ and $\mathrm{WC}-10 \% \mathrm{Co}-4.5 \% \mathrm{C}$ coatings had the highest wear resistance. The wear resistance of the WC-

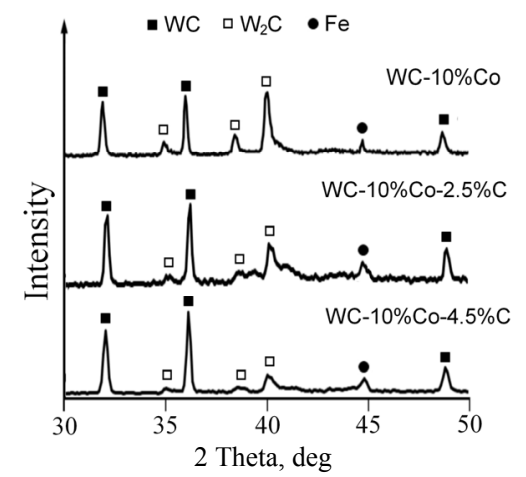

Figure 5. XRD patterns of coatings obtained by electrospark treatment using electrodes with various carbon concentrations at a frequency of $100 \mathrm{~Hz}$.

$10 \%$ Co- $4.5 \% \mathrm{C}$ coating obtained at a higher discharge frequency of $1 \mathrm{kHz}$ was seven times greater than that of a conventional WC- $10 \%$ Co sample.

\section{Conclusion}

We investiged the coatings created by electrospark deposition of WC- $10 \%$ Co alloys with $\mathrm{Al}_{2} \mathrm{O}_{3}$ or carbon additives on steel 35 . Crystallites of tungsten carbide with a size of $1-20$ microns were observed in the obtained coatings. The surface layer had a nanostructured construction. With increasing carbon content in the anode material, the amount of tungsten carbide WC increased. The additives of alumina in the electrode materials based on tungsten carbide allowed us to increase the wear resistance of the coatings. If carbon additives were applied, the microhardness and wear resistance became even greater. This is because with increasing carbon concentration in the anode materials, the decarburization of the tungsten carbide decreased.

\section{Acknowledgements}

The authors thank Dr. A. P. Kuz'menko and Mrs. L. P. Metlickaya for their help with the AFM and metallographic observations. This research was supported by The Ministry of Education and Science of Russia (Grant No. 8687 of the Federal specific-purpose programme "Scientific and scientific-pedagogical personnel of innovative Russia" in the years 2009-2013).

\section{REFERENCES}

[1] N. I. Lazarenko, "Electrospark Coating of Metal Surfaces," M. Mashinostroenie, Russia, 1976, p. 44. (in Russian)

[2] R. N Johnson and G. L. Sheldon, "Advances in the Electrospark Deposition Coating Process," Journal of Vacuum Science \& Technology A: Vacuum, Surfaces, and Films, Vol. 4, No. 6, 1986, pp. 2740-2746. doi: $10.1116 / 1.573672$ 
[3] E. A. Brown, G. L. Sheldon and A. E. Bayoumi, "A Parametric Study of Improving Tool Life by Electrospark Deposition," Wear, Vol. 138, No. 6, 1990, pp. 137-156. doi:10.1016/0043-1648(90)90173-8

[4] A. V. Ribalko and O. Sahin, "A Modern Representation of the Behaviour of Electrospark Alloying of Steel by Hard Alloy," Surface and Coatings Technology, Vol. 201, No. 3-4, 2006, pp. 1724-1730. doi:10.1016/j.surfcoat.2006.02.044

[5] E. A. Levashov, E. I. Zamulaeva, A. E. Kudryashov, P. V. Vakaev, M. I. Petrzhik and A. Sanz, "Materials Science and Technological Aspects of Electrospark Deposition of Nanostructured WC-Co Coatings onto Titanium Substrates," Plasma Processes and Polymers, Vol. 4, No. 3, 2007, pp. 293-300. doi:10.1002/ppap.200600148

[6] N. Radek and K. Bartkowiak, "Performance Properties of Electro-Spark Deposited Carbide-Ceramic Coatings Modified by Laser Beam," Physics Procedia, Vol. 5, 2010, pp. 417-423. doi:10.1016/j.phpro.2010.08.163

[7] E. I. Zamulaeva, E. A. Levashov, A. E. Kudryashov, P. V. Vakaev and M. I. Petrzhik, "Electrospark Coatings Deposited onto an Armco Iron Substrate with Nano- and Microstructured WC-Co Electrodes: Deposition Process,
Structure, and Properties," Surface and Coatings Technology, Vol. 202, No. 15, 2008, pp. 3715-3722. doi:10.1016/j.surfcoat.2008.01.008

[8] R. J. Wang, Y. Y. Qian and J. Liu, "Interface Behavior Study of WC92-Co8 Coating Produced by Electrospark Deposition," Applied Surface Science, Vol. 240, No. 1-4, 2005, pp. 42-47. doi:10.1016/j.apsusc.2004.05.299

[9] S. V. Nikolenko, A. D. Verkhoturov and M. I. Dvornik, "Use of Nanopowder $\mathrm{Al}_{2} \mathrm{O}_{3}$ as the Inhibitor of the Grain Growth in WC-8\%Co Alloy," Voprosju Materialovedenia, No. 2, 2008, p. 100. (in Russian)

[10] P. Bague, J. P. Morizot and G. Desgardin, "Evidence for the Phenomenon of Carburization-Decarburization of Tungsten Carbide," Journal of Physics D: Applied Physics, Vol. 27, No. 2, 1994, pp. 402-406. doi:10.1088/0022-3727/27/2/034

[11] J. M. Guilemany, S. Dosta and J. R. Miguel, "The Enhancement of the Properties of WC-Co HVOF Coatings through the Use of Nanostructured and Microstructured Feedstock Powders," Surface and Coatings Technology, Vol. 201, No. 3-4, 2006, pp. 1180-1190. doi:10.1016/j.surfcoat.2006.01.041 